\title{
BMJ Open Geographic variation in the treatment of non-ST-segment myocardial infarction in the English National Health Service: a cohort study
}

\author{
T B Dondo, ${ }^{1}$ M Hall, ${ }^{1}$ A D Timmis, ${ }^{2}$ A T Yan, ${ }^{3}$ P D Batin, ${ }^{4}$ G Oliver, ${ }^{5}$ O A Alabas, ${ }^{1}$ \\ $\mathrm{P}$ Norman, ${ }^{6} \mathrm{~J}$ E Deanfield, ${ }^{7} \mathrm{~K}$ Bloor, ${ }^{8} \mathrm{H}$ Hemingway, ${ }^{9} \mathrm{C} \mathrm{P}$ Gale ${ }^{1,10}$
}

To cite: Dondo TB, Hall M, Timmis AD, et al. Geographic variation in the treatment of non-ST-segment myocardial infarction in the English National Health Service: a cohort study. BMJ Open 2016;6:e011600. doi:10.1136/bmjopen-2016011600

- Prepublication history and additional material is available. To view please visit the journal (http://dx.doi.org/ 10.1136/bmjopen-2016011600).

Received 23 February 2016 Revised 3 May 2016 Accepted 20 May 2016

CrossMark

For numbered affiliations see end of article.

Correspondence to

Dr C P Gale;

c.p.gale@leeds.ac.uk

\section{ABSTRACT}

Objectives: To investigate geographic variation in guideline-indicated treatments for non-ST-elevation myocardial infarction (NSTEMI) in the English National Health Service (NHS).

Design: Cohort study using registry data from the Myocardial Ischaemia National Audit Project.

Setting: All Clinical Commissioning Groups (CCGs) $(\mathrm{n}=211)$ in the English NHS.

Participants: 357228 patients with NSTEMI between 1 January 2003 and 30 June 2013.

Main outcome measure: Proportion of eligible NSTEMI who received all eligible guideline-indicated treatments (optimal care) according to the date of guideline publication.

Results: The proportion of NSTEMI who received optimal care was low (48 257/357 228; 13.5\%) and varied between CCGs (median 12.8\%, IQR $0.7-18.1 \%)$. The greatest geographic variation was for aldosterone antagonists $(16.7 \%, 0.0-40.0 \%)$ and least for use of an ECG (96.7\%, 92.5-98.7\%). The highest rates of care were for acute aspirin (median $92.8 \%$, IQR 88.6-97.1\%), and aspirin (90.1\%, 85.1-93.3\%) and statins $(86.4 \%, 82.3-91.2 \%)$ at hospital discharge. The lowest rates were for smoking cessation advice (median $11.6 \%$, IQR $8.7-16.6 \%)$, dietary advice (32.4\%, 23.9$41.7 \%)$ and the prescription of $\mathrm{P}_{2} \mathrm{Y}_{12}$ inhibitors $(39.7 \%$, 32.4-46.9\%). After adjustment for case mix, nearly all $(99.6 \%)$ of the variation was due to between-hospital differences (median 64.7\%, IQR 57.4-70.0\%; betweenhospital variance: $1.92,95 \% \mathrm{Cl} 1.51$ to 2.44 ; interclass correlation $0.996,95 \% \mathrm{Cl} 0.976$ to 0.999 ).

Conclusions: Across the English NHS, the optimal use of guideline-indicated treatments for NSTEMI was low. Variation in the use of specific treatments for NSTEMI was mostly explained by between-hospital differences in care. Performance-based commissioning may increase the use of NSTEMI treatments and, therefore, reduce premature cardiovascular deaths.

Trial registration number: NCT02436187.

\section{INTRODUCTION}

Non-ST-elevation myocardial infarction (NSTEMI) is a leading cause of emergency

\section{Strengths and limitations of this study}

- This study evaluated care across a national healthcare service and used a clinical registry designed specifically to evaluate quality of non-ST-elevation myocardial infarction (NSTEMI) care.

- Advanced statistical techniques that allowed high-resolution analysis of combinations of pathways of care according to their eligibility and receipt were used.

- A detailed 10-year evaluation of receipt of carefew other national data sets can offer.

- Myocardial Ischaemia National Audit Project does not collect all cases of NSTEMI; thus, results of underuse of care interventions maybe underestimated.

- We used CCGs to investigate consistency in geographic unit performance over time, when they only recently have replaced Primary Care Trusts and may not have the same Cartesian boundaries.

hospitalisation in Europe and accounts for over 50000 National Health Service (NHS) admissions per year. ${ }^{1-3}$ Mortality rates following NSTEMI are high, worse than that for ST-elevation myocardial infarction, and its incidence (which is already higher than STEMI $)^{45}$ is increasing with an ageing and multimorbid population. ${ }^{6}{ }^{7}$ However, clinical outcomes from NSTEMI may be improved through the use of guideline-indicated treatments including evidence-based pharmacological therapies and invasive coronary procedures. ${ }^{8}$

While hospitals are the cornerstone of the management of acute myocardial infarction, for many countries, treatments are determined by the local contracting of specialist services including that of ambulances, emergency departments and acute cardiac care. For the NHS of England, this is the 
responsibility of the 211 Clinical Commissioning Groups (CCGs) who work in partnership with hospitals, via Strategic Clinical Networks (SCNs) for National Institute for Health and Care Excellence support for commissioning for NSTEMI. ${ }^{3}$

Our earlier work found evidence for variation within and between the UK and Sweden in treatments and 30-day mortality from acute myocardial infarction. ${ }^{1} 29$ Such variation in cardiac services is estimated to cost the NHS $£ 184$ million. ${ }^{10}$ We have also shown that the majority of patients with acute myocardial infarction fail to receive at least one guideline-indicated treatment and that these missed opportunities were associated with cardiovascular deaths. ${ }^{12}$ For NSTEMI-the most common and vulnerable type of acute myocardial infarctioninformation concerning variation in guideline-indicated treatments is very limited. ${ }^{13-17}$ For the English NHS, there are no reports of how NSTEMI treatments vary according to CCGs, which leaves a gap in our knowledge as to how and where to focus efforts on reducing premature death from cardiovascular disease. Therefore, we used the UK heart attack register (Myocardial Ischaemia National Audit Project, MINAP) to conduct a 10-year study of the geographic variation in guideline-indicated treatments for NSTEMI.

\section{METHODS}

\section{Setting and design}

We included all NHS hospitals $(n=232)$ in England which provided care for patients $(n=357228)$ aged over 18 years with NSTEMI between 1 January 2003 and 30 June 2013. The diagnosis of NSTEMI was based on guidelines from the European Society of Cardiology (ESC), American College of Cardiology and American Heart Association and determined at local level by the attending Consultant. ${ }^{18}$ For multiple admissions, we used the earliest record. Patient-level data concerning demographics, cardiovascular risk factors, medical history and clinical characteristics at the time of hospitalisation were extracted from MINAP, a comprehensive registry of hospitalisations for acute coronary syndrome in England and Wales, which was started in 2000 and is now mandated by the Department of Health. ${ }^{19}$ Details of MINAP have been described previously. ${ }^{11}$ The data flow for the derivation of the analytical cohort can be seen in figure 1.

\section{Patient involvement}

No patients were involved in the design or implementation of the study. However, we involved a patient in the interpretation of the research and the writing of the research manuscript.

\section{Quality of care}

We mapped iterative ESC guidelines for the management of NSTEMI and ESC Expert Consensus Documents to MINAP data to identify 13 guideline-indicated treatments as they became available over the study period. ${ }^{20-25}$ They included: the recording of an ECG, acute provision of aspirin, at hospital discharge the prescription of $\mathrm{P}^{2} \mathrm{Y}_{12}$ inhibitors, aspirin, $\beta$ blockers among patients with left ventricular systolic dysfunction, ACE inhibitors (ACEis)/ angiotensin receptor blockers (ARBs) among patients with left ventricular systolic dysfunction, aldosterone antagonists among patients with left ventricular dysfunction and either diabetes or heart failure without significant renal dysfunction, HMG-CoA reductase enzyme inhibitors (statins), and the use of early invasive procedures (coronary angiography), echocardiography, smoking cessation advice, dietary advice and enrolment into a cardiac rehabilitation programme. ${ }^{821}$ We assessed the receipt of guideline-indicated treatments only for patients who were deemed eligible for each treatment according to the ESC guidelines. ${ }^{20} 21$ 23-25 Patients were also classified as ineligible if a treatment was contraindicated, not indicated, not applicable, if the patient declined treatment as recorded in MINAP or if the patient was hospitalised prior to the time the treatment was recommended by the guidelines. See online supplementary tables S1 and figure S1 for information about how the ESC guidelines for the management of NSTEMI were mapped to MINAP data.

\section{Geographic units}

We mapped each patient's treatment data, located by eastings and northings supplied by MINAP, to the April 2015 Geographic Information System CCGs layers (accessed from NHS England) and created choropleth maps to show the distribution of receipt of guidelineindicated treatments using ArcGIS V.10.2.2. We used class intervals with equal cut-offs for categorisation.

\section{Statistical analysis}

We assessed the overall provision of guideline-indicated treatment by constructing composite scores for each patient. To do this, we divided the total number of treatments received by a patient by the total number of treatments that the patient was eligible for. ${ }^{26-28}$ Optimal care was defined as receiving all (up to 13) guidelineindicated treatments for which patients were eligible. We dichotomised the score as receipt of optimal care and non-receipt of optimal care (suboptimal care). Furthermore, the composite scores were categorised as high receipt $(>79 \%)$, intermediate $(40$ to $\leq 79 \%)$ and low $(\leq 40 \%)$ according to recognised cut-offs. ${ }^{29}{ }^{30}$ For optimal care and each of the 13 ESC guideline-indicated treatments in turn, we calculated the proportion of patients who received the treatment according to their location in a geographic unit. For example, for aspirin, this would be 'did the patient, who was eligible to receive and had no contraindications, receive aspirin?'

We used percentages to describe categorical variables and means and SDs or medians, IQRs and ranges for continuous normally distributed and non-normally distributed variables, respectively. We used Spearman's 
Figure 1 STROBE diagram of the derivation of the analytical cohort from the MINAP data set. MINAP, Myocardial Ischaemia National Audit Project; NSTEMI, non-ST-segment elevation myocardial infarction.

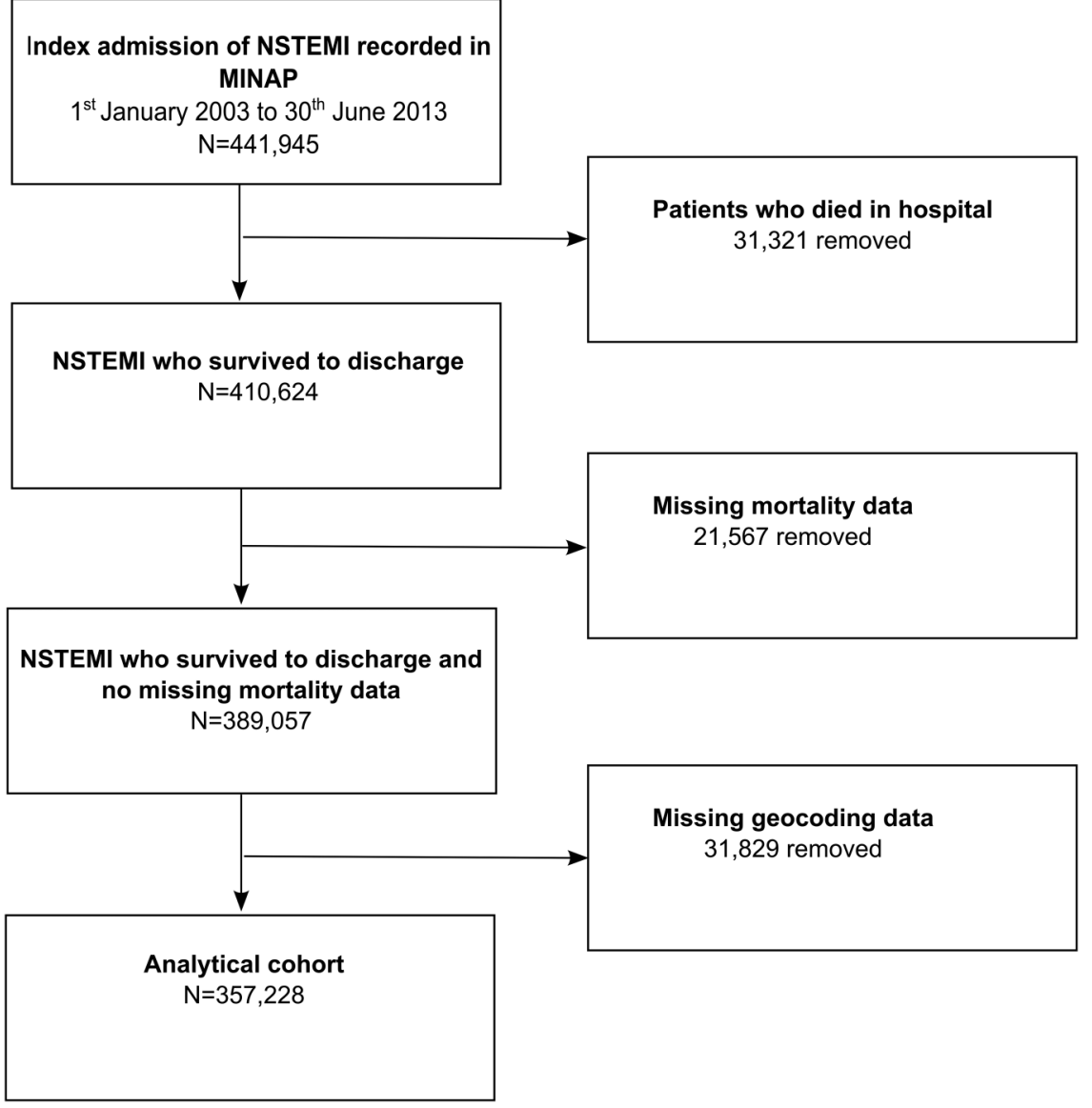

correlation to assess the relationship between receipt of care in the earlier years (2003-2004) and receipt of care in the later years (2012-2013) by CCGs. We also represented temporal changes in optimal care among CCGs using Google Charts and motion maps.

To quantify variation within and between the geographic units, we used a four-level hierarchical Poisson model $^{31}$ comprising patients nested within hospitals, nested within CCGs and nested within SCNs. The outcome (receipt of optimal care) was modelled as a count variable with a conditional Poisson distribution and all NSTEMI patients in the cohort as the exposure. The model incorporated patient-specific characteristics as fixed effects including demographics (sex, Index of Multiple Deprivation score and ethnicity), cardiovascular risk factors (diabetes, hypercholesterolaemia, hypertension, smoking status, asthma/chronic obstructive pulmonary disease (COPD) and family history of coronary heart disease), cardiovascular history (previous myocardial infarction, heart failure, percutaneous coronary intervention, coronary artery bypass grafting, angina, cerebrovascular disease and peripheral vascular disease) and the mini-GRACE risk score for predicted 6-month mortality. ${ }^{32}$ In addition, hospital, CCG and SCN random effects were included in the model to allow for clustering of patients within these levels. The intercept provided each patient's expected rate of guideline-indicated treatments (with a log transformation), adjusted for case mix. We used the interclass correlation (ICC) to quantify the proportion of variation in guideline-indicated treatments that was attributable to hospitals, CCGs and SCNs after adjustment for patient-specific characteristics. All analyses were performed using Stata V.13.

\section{Excess deaths}

Multilevel accelerated failure time models were used to identify the association between missed guidelineindicated treatments and time to all-cause mortality. All models included a shared frailty term to account for clustering of patients within hospitals. Models were adjusted for case mix using the adjusted mini-GRACE risk score $^{32}$ and for baseline patient characteristics including: previous history of myocardial infarction, angina, diabetes, hypertension, peripheral vascular disease, family history of coronary heart disease, asthma/COPD, hypercholesterolaemia and coronary revascularisation. Models were fitted on imputed data and estimates pooled over 10 imputations (see online supplementary table S2). In order to determine the potentially preventable deaths associated with suboptimal treatment for hospitals, the adjusted mortality risk (see online supplementary table S3) obtained from the multilevel accelerated failure time models was multiplied by the corresponding mortality rates and proportions of patients in the suboptimal treatment groups per hospital. The product was then multiplied by the total 
number of NSTEMI between 2003 and 2013 for each hospital (see online supplementary section 3).

\section{RESULTS}

Of 357228 patients with NSTEMI (mean age 70.9 (SD $13.3)$ years $), 63.1 \%$ ( $n=225009)$ were men, the majority $(93.1 \%, n=301312)$ were white, one-third had angina and a quarter had previous myocardial infarction (table 1).
Over half $(\mathrm{n}=254215,71.2 \%)$ were previous or current smokers, $48.9 \%(\mathrm{n}=174596)$ had hypertension, 21.1\% ( $\mathrm{n}=75433)$ diabetes and $14.6 \%(\mathrm{n}=52030)$ had asthma or COPD. Over $2 \%(n=7280)$ of patients had an admission systolic blood pressure $<90 \mathrm{~mm} \mathrm{Hg}$. About half $(n=184631,56.8 \%)$ of all electrocardiographic changes were ST-segment deviation or T-wave inversion with $15.7 \% \quad(n=51214)$ of patients having no acute

Table 1 Baseline characteristics, NSTEMI, 2003-2013

\begin{tabular}{|c|c|c|}
\hline Characteristics & $\begin{array}{l}\text { Cases } \\
n=357228\end{array}$ & Missing \\
\hline Age, years; mean (SD) & $70.9(13.3)$ & $504(0.1)$ \\
\hline Male & 225009 (63.1) & $593(0.2)$ \\
\hline \multicolumn{3}{|l|}{ Deprivation according to IMD score } \\
\hline 1 (least deprived) & 61235 (17.2) & $419(0.1)$ \\
\hline 2 & 70084 (19.6) & \\
\hline 3 & $74842(21.0)$ & \\
\hline 4 & $72121(20.2)$ & \\
\hline 5 (most deprived) & 78527 (22.0) & \\
\hline \multicolumn{3}{|l|}{ Prior medical history } \\
\hline Myocardial infarction & $89571(25.1)$ & $0^{*}$ \\
\hline Heart failure & $22581(6.3)$ & $0^{*}$ \\
\hline $\mathrm{PCl}$ & $30835(8.6)$ & $0^{*}$ \\
\hline CABG & $26021(7.3)$ & $0^{*}$ \\
\hline Angina & 113059 (31.7) & $0^{*}$ \\
\hline Cerebrovascular disease & $31366(8.8)$ & $0^{*}$ \\
\hline Peripheral vascular disease & $16868(4.7)$ & $0^{*}$ \\
\hline Diabetes & $75433(21.1)$ & $0^{*}$ \\
\hline Chronic renal failure & $20349(5.7)$ & $0^{*}$ \\
\hline Hypercholesterolaemia & $112713(31.5)$ & $0^{*}$ \\
\hline Hypertension & $174596(48.9)$ & $0^{*}$ \\
\hline Previous or current smoker & $254215(71.2)$ & $0^{*}$ \\
\hline Asthma or COPD & $52030(14.6)$ & $0^{*}$ \\
\hline Family history of CHD & $72444(20.3)$ & $0^{*}$ \\
\hline \multicolumn{3}{|l|}{ Presenting characteristics } \\
\hline Systolic blood pressure, mm Hg, mean (SD) & $142.5(28.4)$ & $59962(16.8)$ \\
\hline Systolic blood pressure, $<90 \mathrm{~mm} \mathrm{Hg}$ & $7280(2.5)$ & $59962(16.8)$ \\
\hline Heart rate, bpm, mean (SD) & $80(67-95)$ & $59177(16.6)$ \\
\hline Heart rate $>110 \mathrm{bpm}$ & $32964(11.1)$ & 59177 (16.9) \\
\hline Creatinine; mean (SD) & $92(76-114)$ & $147959(41.4)$ \\
\hline Troponin elevation & $321212(94.6)$ & $17559(4.9)$ \\
\hline Cardiac arrest & $6178(1.8)$ & $21038(5.9)$ \\
\hline \multicolumn{3}{|l|}{ ECG } \\
\hline No acute changes & $51214(15.7)$ & 31825 (8.9) \\
\hline ST-segment elevation & $14336(4.4)$ & \\
\hline Left bundle branch block & $21149(6.5)$ & \\
\hline ST-segment depression & $84821(26.1)$ & \\
\hline T-wave changes only & 85474 (26.3) & \\
\hline Other acute abnormality & $68409(21.0)$ & \\
\hline Use of a loop diuretic & $89438(30.2)$ & $61294(17.1)$ \\
\hline \multicolumn{3}{|l|}{ GRACE risk score category } \\
\hline Low $(\leq 88)$ & 25787 (18.2) & $215599(60.4)$ \\
\hline Intermediate (88-110) & 38897 (27.5) & \\
\hline High $(>110)$ & $76945(54.3)$ & \\
\hline
\end{tabular}

GRACE risk score category as defined by NICE.

*Missing data default imputed to 'No'.

CABG, coronary artery bypass graft; CHD, coronary heart disease; COPD, chronic obstructive pulmonary disease; IMD, Index of Multiple Deprivation; NICE, National Institute for Health and Care Excellence; NSTEMI, non-ST-segment elevation myocardial infarction; PCI, percutaneous coronary intervention. 
changes. According to the mini-GRACE risk score, 8 in 10 patients were in intermediate or high risk. The distribution of patients eligible to receive guideline-indicated treatments is shown in table 2, the highest being for an ECG and the lowest for smoking cessation advice.

\section{Guideline-indicated interventions}

The proportion of NSTEMI who received optimal care was low $(48257 / 357228,13.5 \%)$. One in $10(n=42229$, $11.8 \%$ ) received $\leq 40 \%$ of the guideline-indicated treatments for which they were eligible, 6 in $10 \quad(n=208930$, $58.5 \%)$ received $>40 \%$ to $\leq 79 \%$ and 3 in $10 \quad(n=106069$, $29.7 \%$ ) received $>79 \%$. The most frequently missed were dietary advice $(\mathrm{n}=231201,67.4 \%)$, smoking cessation advice $\quad(\mathrm{n}=222532, \quad 87.5 \%), \quad$ echocardiography $\left(\mathrm{n}=178\right.$ 344, 49.9\%), $\mathrm{P}_{12} \mathrm{Y}_{12}$ inhibitors at discharge from hospital ( $\mathrm{n}=175023,59.0 \%)$, coronary angiography $(\mathrm{n}=146075,42.6 \%)$ and in-hospital aspirin $(\mathrm{n}=97411$, $44.8 \%$ ) (table 2). Over half of the patients $(\mathrm{n}=207355$, $58.1 \%$ ) were not under the care of a cardiologist.

\section{Geographic variation}

For CCGs, the proportion of patients who received optimal care was low (median 12.8\%, IQR $0.7-18.1 \%$ ) (figure 2). The greatest variation in care was for aldosterone antagonists (median 16.7\%, IQR $0.0-40.0 \%$ ) and least for use of an ECG $(96.7 \%, 92.5-98.7 \%)$. High rates of the prescription of aspirin acutely (median 92.8\%, IQR 88.6-97.1\%), aspirin at discharge from hospital (90.1\%, $85.1-93.3 \%)$ and statins $(86.4 \%, 82.3-91.2 \%)$ were consistent. The provision of echocardiography (50.3\%, $38.3-61.9 \%)$, cardiac rehabilitation $(79.7 \%, 68.2-87.1 \%)$, coronary angiography $(57.4 \%, 48.8-66.7 \%)$, the prescription of ACEis/ARBs $(69.0 \%, 63.6-74.0 \%)$ and $\beta$ blockers $(76.3 \%, 70.4-82.0 \%)$ was intermediate and varied widely, while the provision of smoking cessation advice $(11.6 \%$,
8.7-16.6\%), dietary advice $(32.4 \%, 23.9-41.7 \%)$ and $\mathrm{P} 2 \mathrm{Y}_{12}$ inhibitors $(39.7 \%, 32.4-46.9 \%)$ was poor.

Across SCNs, the proportion of patients who received optimal care was also low (median 12.2\%, IQR 11.5$15.9 \%$ ) (see online supplementary table S4). The area with the highest proportion of patients who received optimal care was North East and North Cumbria ( $\mathrm{n}=7045$, $20.0 \%)$, and the lowest was the East Midlands ( $\mathrm{n}=3409$, $10.3 \%)$. Rates of guideline-indicated interventions were intermediate-to-high and varied little between SCNs for ECG (median 95.0\%, IQR 92.0-96.0\%), acute aspirin $(91.0 \%, 88.0-92.0 \%)$, statins $(86.0 \%, 84.0-87.0 \%)$, aspirin on discharge $(89.0 \%, 87.0-90.0 \%)$, cardiac rehabilitation $(79.0,72.0-82.0 \%), \beta$ blockers $(76.0 \%$, $73.0-76.0 \%)$ and the prescription of ACEis/ARBs $(68.0 \%, 67.0-70.0 \%)$. Performance was consistently low across SCNs for $\mathrm{P}^{2} \mathrm{Y}_{12}$ inhibitors $(40.0 \%, 39.0-42.0 \%)$, aldosterone antagonists $(27.0 \%, 20.0-28.0 \%)$, smoking cessation advice $(13.0 \%, 12.0-17.0 \%)$ and dietary advice $(32.0 \%, 28.0-37.0 \%)$. Echocardiography $(50.0 \%, 45.0$ $55.0 \%)$ and coronary angiography $(58.0 \%, 52.0-61.0 \%)$ were provided at an intermediate rate.

\section{Variance components}

The between-unit variance, standardised for case mix, was low for SCNs $(0.004,95 \%$ CI 0.0004 to 0.03$)$ and CCGs $(0.004,0.001$ to 0.03$)$ but much higher for hospitals $(1.92,95 \%$ CI 1.51 to 2.44$)$. Moreover, the model indicated that $0.2 \%$ of the remaining variation in the provision of guideline-indicated care after case mix adjustment was between SCNs (ICC 0.002, 95\% CI 0.0002 to 0.01 ) and $0.2 \%$ between CCGs (ICC 0.002, $95 \%$ CI 0.0007 to 0.01 ) with $99.6 \%$ between hospitals (ICC 0.996, 95\% CI 0.976 to 0.999) (table 3). Hospital variation in optimal care was consistently wide within SCNs of differencing performance (figure 3).

Table 2 Eligibility and receipt of guideline-indicated interventions, NSTEMI, 2003-2013

\begin{tabular}{lcc}
\hline $\begin{array}{l}\text { Guideline-indicated } \\
\text { intervention }\end{array}$ & $\begin{array}{l}\text { Number }(\%) \text { of NSTEMI who } \\
\text { received a guideline-indicated } \\
\text { intervention }\end{array}$ & $\begin{array}{l}\text { Number of NSTEMI eligible for } \\
\text { a guideline-indicated } \\
\text { intervention }\end{array}$ \\
\hline ECG & $336094(94.1)$ & 357228 \\
Acute aspirin & $212837(88.7)$ & 239876 \\
Echocardiography & $178851(50.1)$ & 357195 \\
Coronary angiography & $196781(57.4)$ & 342856 \\
Aspirin at discharge & $279584(89.1)$ & 313901 \\
P2Y ${ }_{12}$ inhibitors & $121427(41.0)$ & 296450 \\
ACEis/ARBs & $81176(67.9)$ & 119625 \\
$\beta$ Blockers & $80600(74.8)$ & 107698 \\
Statins at discharge & $275626(86.2)$ & 319747 \\
Aldosterone antagonists & $134(23.7)$ & 566 \\
Dietary advice & $111759(32.6)$ & 342960 \\
Smoking cessation advice & $31683(12.5)$ & 254215 \\
Cardiac rehabilitation & $257875(76.7)$ & 336146 \\
\hline ACEis, ACE inhibitors; ARB, angiotensin receptor blockers. &
\end{tabular}



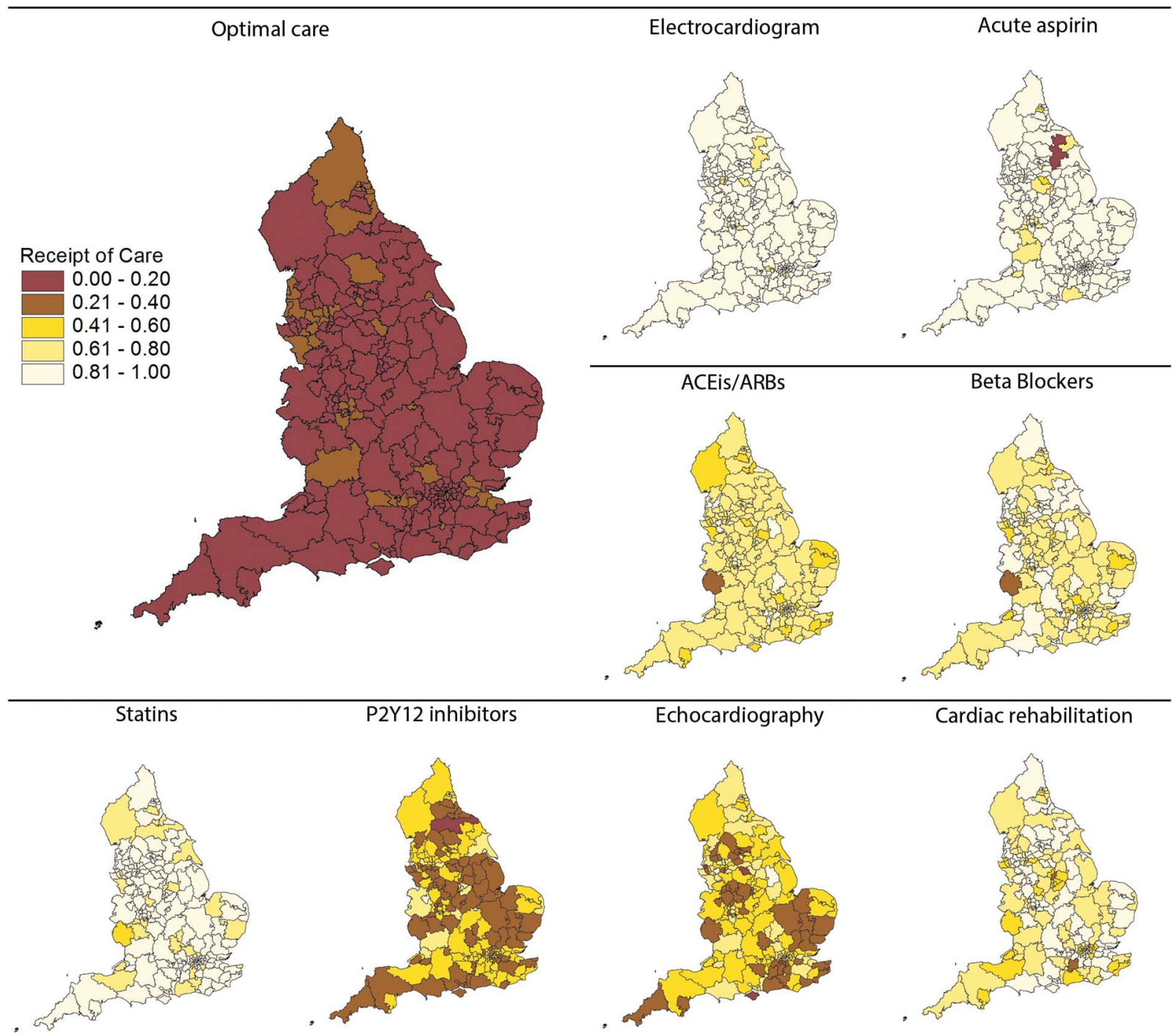

Echocardiography

Cardiac rehabilitation

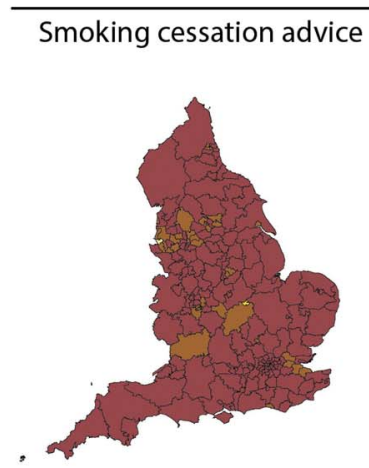

Dietary advice
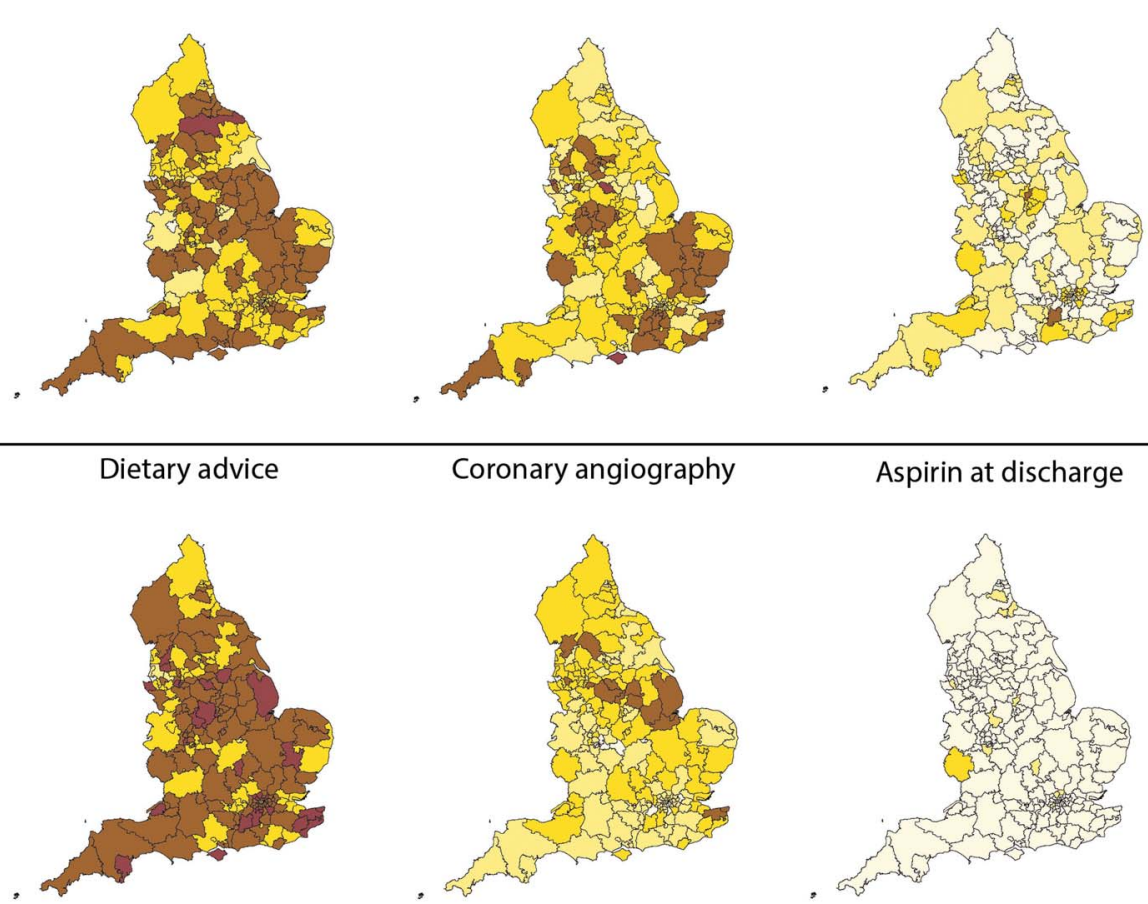

Aspirin at discharge

Figure 2 Geographic variation proportions of eligible patients who received guideline-indicated interventions, for each intervention and for optimal care, by CCG. ACEis, ACE inhibitors; ARB, angiotensin receptor blockers; CCGs, Clinical Commissioning Groups.

\section{Temporal changes}

Table 4 shows the improvement in the provision NSTEMI care from $2003 / 2004$ to $2012 / 2013$, being most pronounced for coronary angiography (median CCG rates: 33 vs $83 \%$ ), ACEis/ARBs (71 vs 100\%) and $\beta$ blockers (77 vs $100 \%$ ). Even so, there was only a modest improvement in optimal care, and although the correlation between care in CCGs over the study period was significant, it was weak $(\rho=0.36, p<0.001)$. Temporal trends in the proportion of NSTEMI who received guideline-indicated treatments between 2003 and 2013 are shown in interactive figures 4 and 5 which can be accessed by clicking on the 
Table 3 Parameter estimates, p values, SEs and 95\% Cls for optimal receipt of care for the Poisson model

\begin{tabular}{|c|c|c|c|}
\hline Fixed effects & Incidence ratios & p Value & $95 \% \mathrm{Cl}$ \\
\hline Sex (male vs female) & 1.12 & $<0.001$ & 1.11 to 1.15 \\
\hline \multicolumn{4}{|l|}{ Deprivation according to IMD score } \\
\hline 1 (least deprived) & 1 & - & 1 \\
\hline 2 & 0.98 & 0.34 & 0.95 to 1.02 \\
\hline 3 & 0.99 & 0.41 & 0.95 to 1.02 \\
\hline 4 & 0.97 & 0.06 & 0.93 to 1.00 \\
\hline 5 (most deprived) & 0.96 & 0.02 & 0.92 to 0.99 \\
\hline \multicolumn{4}{|l|}{ Ethnicity } \\
\hline White & 1 & - & 1 \\
\hline Black & 0.99 & 0.78 & 0.90 to 1.08 \\
\hline Asian & 1.02 & 0.32 & 0.98 to 1.07 \\
\hline Mixed & 1.21 & 0.07 & 0.98 to 1.48 \\
\hline Other & 0.92 & 0.10 & 0.84 to 1.02 \\
\hline \multicolumn{4}{|l|}{ GRACE risk score category } \\
\hline Low $(\leq 88)$ & 1 & - & 1 \\
\hline Intermediate (88-110) & 0.97 & 0.16 & 0.94 to 1.01 \\
\hline High $(>110)$ & 0.78 & $<0.001$ & 0.76 to 0.81 \\
\hline Current smoker (Yes vs No) & 1.16 & $<0.001$ & 1.14 to 1.19 \\
\hline Prior diabetes (Yes vs No) & 0.99 & 0.88 & 0.98 to 1.02 \\
\hline Prior Ml (Yes vs No) & 0.90 & $<0.001$ & 0.88 to 0.92 \\
\hline Prior angina (Yes vs No) & 0.91 & $<0.001$ & 0.89 to 0.93 \\
\hline Prior PCl (Yes vs No) & 0.98 & 0.33 & 0.95 to 1.02 \\
\hline Prior CABG (Yes vs No) & 0.95 & 0.01 & 0.92 to 0.99 \\
\hline Prior peripheral vascular disease (Yes vs No) & 0.95 & 0.03 & 0.91 to 0.99 \\
\hline Hypercholesterolemia & 1.11 & $<0.001$ & 1.08 to 1.13 \\
\hline Prior hypertension (Yes vs No) & 1.02 & 0.08 & 1.00 to 1.04 \\
\hline Prior cerebrovascular disease (Yes vs No) & 0.88 & $<0.001$ & 0.84 to 0.90 \\
\hline Prior chronic obstructive pulmonary disease/asthma (Yes vs No) & 0.94 & $<0.001$ & 0.92 to 0.97 \\
\hline Family history of CHD (Yes vs No) & 1.15 & $<0.001$ & 1.13 to 1.17 \\
\hline Year & 1.60 & $<0.001$ & 1.60 to 1.62 \\
\hline Random effects & Variance & Standard error & $95 \% \mathrm{Cl}$ \\
\hline \multicolumn{4}{|l|}{ Hospital variance } \\
\hline & 1.92 & 0.24 & 1.51 to 2.44 \\
\hline \multicolumn{4}{|l|}{ CCG variance } \\
\hline & 0.004 & 0.004 & 0.001 to 0.03 \\
\hline \multirow[t]{2}{*}{ SCN variance } & & & \\
\hline & 0.004 & 0.004 & 0.0004 to 0.03 \\
\hline
\end{tabular}

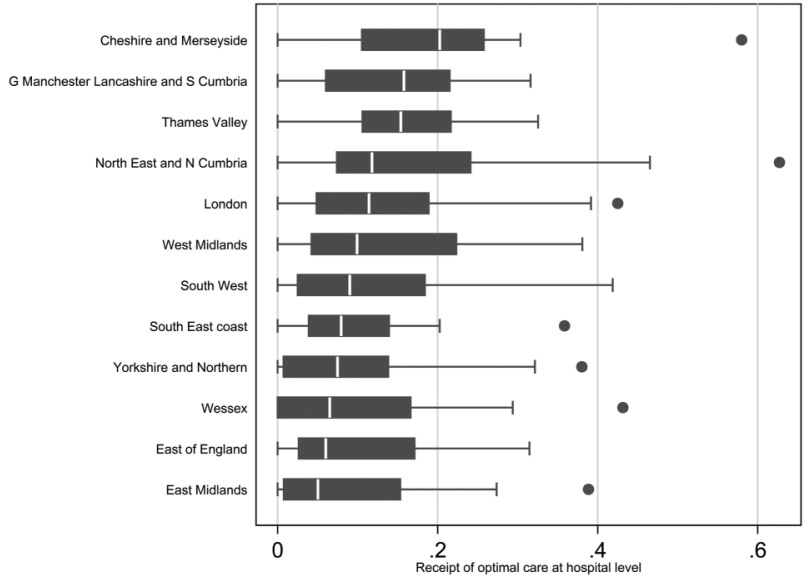

Figure 3 Optimal care variation in hospitals by SCNs. SCNs, Strategic Clinical Networks. following web links: http://www.personal.leeds.ac.uk/ $\sim$ medcardp/googleplots.html and http://www.personal. leeds.ac.uk/ medcardp/map.html respectively.

\section{Excess deaths}

Over the study period, the case mix standardised excess mortality associated with non-receipt of optimal guidelineindicated care varied between hospitals (median number of deaths 39, IQR 15-62) between 2003 and 2013.

\section{DISCUSSION}

Over a 10-year study period, we found evidence for widespread suboptimal use of guideline-indicated treatments for the management of NSTEMI. While the use of specific treatments for NSTEMI, such as pharmacological 
Table 4 Temporal changes in the proportion of NSTEMI receiving guideline-indicated treatments, 2003/2004 vs 2012/2013 in CCGs

\begin{tabular}{|c|c|c|}
\hline \multirow[b]{2}{*}{$\begin{array}{l}\text { Guideline-indicated } \\
\text { intervention }\end{array}$} & \multicolumn{2}{|l|}{ Biennial year } \\
\hline & $\begin{array}{l}\text { 2003/2004 } \\
\text { Median (IQR) }\end{array}$ & $\begin{array}{l}\text { 2012/2013 } \\
\text { Median (IQR) }\end{array}$ \\
\hline Optimal care & 0.00 & $0.34(0.23-0.46)$ \\
\hline ECG & $0.86(0.69-0.96)$ & $1.00(0.99-1.00)$ \\
\hline Acute aspirin & $0.88(0.8$ & $0.97(0$ \\
\hline ACEis/ARBs & $0.71(0.65-0.76)$ & 1.00 \\
\hline$\beta$ Blocke & & $3-1.00)$ \\
\hline Statins & $0.83(0.77-0.88)$ & $1-0.98)$ \\
\hline $\mathrm{P}_{2} \mathrm{Y}_{12}$ inhibitors & 0.00 & \\
\hline $\begin{array}{l}\text { Aldosterone } \\
\text { antagonist }\end{array}$ & - & \\
\hline ardiography & $0.41(0.27-0.57)$ & $0.63(0.51-0.76)$ \\
\hline Cardi & 0.73 & \\
\hline $\begin{array}{l}\text { Smoking cessation } \\
\text { advice }\end{array}$ & 0.00 & $0.69(0.47-0.87)$ \\
\hline Dietary advice & & \\
\hline $\begin{array}{l}\text { Coronary } \\
\text { angiography }\end{array}$ & $0.33(0.21-0.47)$ & $0.83(0.75-0.89)$ \\
\hline Aspirin on discharge & $0.89(0.83-0.93)$ & $0.97(0.94-0.99)$ \\
\hline
\end{tabular}

Median represents the median of the proportion of eligible NSTEMI who received guideline-indicated care.

ACEis, ACE inhibitors; ARB, angiotensin receptor blockers; CCGs, Clinical Commissioning Groups; NSTEMI, non-ST-segment elevation myocardial infarction.

therapies and invasive coronary procedures, varied between CCGs, most of the variation (after accounting for differences in patients) was explained by differences in the provision of care by hospitals. We found that the geographical variation in NSTEMI treatments was associated with geographical variation in the number of excess deaths. Together, the findings from our study suggest that there is substantial scope to improve the provision and uniformity of NSTEMI care across the NHS and, therefore, reduce premature cardiovascular death.

In contrast to recent reports of geographic and temporal variation in the inappropriate use of cardiac procedures, ${ }^{33}$ we found that many patients who were eligible to receive care did not. The greatest variation was for the prescription of aldosterone antagonists and least for use of an ECG. Specifically, when we defined care using a composite score according to eligibility for any of the 13 international guideline recommended treatments and according to the date from which they were published, we found that optimal care was delivered infrequently. Even though we found that optimal care varied geographically, it was only when we evaluated specific interventions that we found much wider variations in care. This was evidenced by wide variation in the provision of key interventions such as coronary angiography, cardiac rehabilitation and pharmacological therapies.

After adjustment for case mix, most of the variation in NSTEMI care occurred at the level of the hospital and to a much lesser extent between CCGs and SCNs. This finding is not surprising because hospitals are the service providers for the treatment of NSTEMI. Our earlier research has described the missed opportunities for care among patients who present to NHS hospitals with acute myocardial infarction and that this was significantly associated with reduced survival. ${ }^{11,13}$ We have also shown that between-hospital variation in care is wider in the UK than in Sweden, and this was also associated with a higher and wider range of mortality rates in the UK. ${ }^{2}$ For this study, we elected to investigate geographic variation in care according to CCGs rather than hospitals because CCGs are central to the contracting of NSTEMI services and to whom hospitals are financially accountable.

Causes of healthcare variation are numerous and complex. They may be due to differences in patterns of illness, clinicians' behaviour or the effects of incentives in the financing of healthcare. ${ }^{34} 35$ In this study, we found that variation in the provision of NSTEMI treatment remained after adjusting for patient sociodemographic and clinical characteristics. This suggests that modifiable factors such as procurement, infrastructure, availability of specialist services and physician education are critical. ${ }^{34}$ Typically the use and availability of cardiac procedures are closely related. ${ }^{15} 36$ However, this is not always the case and it is possible that other factors are also at play such as physician-dependent risk-aversion to invasive cardiac care, ${ }^{37}$ a perception that higher risk patients do not have a net benefit from NSTEMI care, difficulties in obtaining an early and accurate diagnosis of NSTEMI, ${ }^{38} 39$ the availability of specialist cardiac, emergency and ambulance services staff, size and type of acute hospital $^{40}$ as well as the placement patients with NSTEMI on adequately staffed specialist wards within a hospital. ${ }^{37}$ In addition, we found little evidence to suggest that the performance of a geographic unit remained constant (though overall there was improvement in care over time). Our findings suggest that regional networks of care for NSTEMI are immature and can be compared with the provision of STEMI care in the UK where there is institutional (and regional) operationalisation effecting high-quality care and low mortality rates. ${ }^{40} 41$

Ours and others' previous work have demonstrated significant associations between adherence to evidencebased care for the management of NSTEMI and better clinical outcomes. ${ }^{112642}$ Data from the CRUSADE registry have also shown that patients with NSTEMI who receive guideline-indicated care have better outcomes and that this is associated with the type of hospital to which a patient is admitted. ${ }^{13} 43$ Even though our research concentrated mainly the evaluation of processes of care, we also found that there was variation between hospitals in the numbers of potentially avoidable deaths. This is not a surprising finding because our study was of guideline-indicated treatments endorsed by international societies with mostly Class $1 \mathrm{~A}$ recommendations that have been shown in randomised studies to improve clinical outcomes. ${ }^{8} 44$ Tackling inequalities in 
care at the level of the healthcare professional, service provider and commissioner will lead to a reduction in the numbers of deaths from NSTEMI.

By representing processes of clinical care at the level of the CCG, commissioners may identify where and what service may require closer attention. Moreover, it is plausible that the introduction of a performance-based tariff for NSTEMI (or an additional best practice payment) ${ }^{45}$ may improve outcomes and reduce provider variation. This is because others have reported associations between performance-based commissioning and improved quality of care and outcomes, albeit not for NSTEMI. ${ }^{46-49}$ For example, the introduction of the Advancing Quality programme across all NHS hospitals in the north-west of England was associated with a significant reduction in combined short-term mortality for pneumonia, heart failure and acute myocardial infarction. ${ }^{49}$

Our study has strengths in that it evaluated care across a national healthcare service and accesses a clinical registry designed specifically to evaluate quality of NSTEMI care. Even though variance in adherence to guideline-indicated care for NSTEMI has been reported by others, ${ }^{50}{ }^{51}$ it has not been evaluated across a single healthcare system-which should, therefore, vary to a lesser degree than across different health systems operating in one country. In this study, we undertook a systematic approach to evaluate variation in care. ${ }^{52}$ First, we quantified variability in rates across different layers of geographic units. Second, we calculated indexes, including the systematic component of variation. Third, we developed explanations for the variation by adjusting for case mix. In addition to the main findings, our study is an example of how patient-level clinical registries allow higher resolution interrogation of pathways of care, ${ }^{53}$ the results of which should stimulate bespoke quality improvement tailored to region and intervention.

Our study, however, has limitations. MINAP does not collect all cases of NSTEMI-even so, our study was designed to study the impact of missed care at the level of the patient and not the numbers of NSTEMI hospitalised. We speculate that MINAP captures less than half of all NSTEMI; consequently, the number of missed opportunities that we report will be underestimated. Conversely, it is possible that some patients will have received treatments, but this not recorded in MINAP. We used CCGs to investigate consistency in geographic unit performance over time, when they only recently have replaced Primary Care Trusts and may not have the same Cartesian boundaries. The deficits in care for smoking cessation and dietary advice may be artificially inflated because advice about smoking and diet are implicit in cardiac rehabilitation programmes and there may have been preferencing by coders towards recording cardiac rehabilitation.

In conclusion, this study found that between 2003 and 2013, most of the 357228 patients hospitalised with NSTEMI did not receive optimal international guideline-indicated care, although this finding was less evident in the latter years of study. Receipt of optimal care for the management of NSTEM, and more so the individual components of the NSTEMI treatment pathway, varied widely by hospitals across the English NHS and was associated with between-hospital variation in excess deaths. Given adherence to guideline-indicated care for the management of NSTEMI is associated with improved clinical outcomes, addressing the provision of care through performance-based commissioning and stronger networks of NSTEMI care has the potential to reduce premature deaths from cardiovascular disease.

\section{Author affiliations}

${ }^{1}$ Leeds Institute of Cardiovascular and Metabolic Medicine, Leeds, UK

${ }^{2}$ The National Institute for Health Biomedical Research Unit, Barts Health, London, UK

${ }^{3}$ Department of Medicine, University of Toronto, Toronto, Ontario, Canada ${ }^{4}$ Department of Cardiology, The Mid Yorkshire Hospitals NHS Trust, Wakefield, UK

${ }^{5}$ National Health Service cardiac service user, West Yorkshire, UK

${ }^{6}$ School of Geography, University of Leeds, Leeds, UK

${ }^{7}$ National Institute for Cardiovascular Outcomes Research, University College London, London, UK

${ }^{8}$ Department of Health Sciences, University of York, York, UK

${ }^{9}$ The Farr Institute, University College London, London, UK

${ }^{10}$ York Teaching Hospital NHS Foundation Trust, York, UK

Twitter Follow the University of Leeds at @universityleeds and Paul Norman at @pdqnorman

Acknowledgements The authors gratefully acknowledge the contribution of all hospitals and healthcare professions who participate in the MINAP registry. The authors acknowledge the MINAP Academic Group and the National Institute for Cardiovascular Outcomes Research (NICOR) for their contribution to this research and to the funders including the British Health Foundation, National Institute for Health Research and the Medical Research Council. Further, the authors thank Mr David Batty, IT Support, Leeds Institute for Data Analytics, for his support in developing the interactive choropleth maps and motion plots which supplement this manuscript.

Contributors TBD analysed the data and drafted the manuscript. CPG, OAA and $\mathrm{MH}$ provided scientific input. CPG, ADT, HH, JED, ATY and PDB provided expert clinical advice and interpretation of the data. KB provided expert guidance on health policy and delivery of healthcare and interpretation of the data. PN geocoded MINAP data and produced choropleth maps. GO was involved as a patient advisor in the interpretation of the research and the writing of the manuscript. All authors made critical revisions and provided intellectual content to the manuscript, approved the final version to be published and agreed to be accountable for all aspects of the work. CPG is the guarantor for this study.

Funding This research was funded by the British Heart Foundation (Project Grant PG/13/81/30474). MH and TBD are funded by the British Heart Foundation (Project Grant PG/13/81/30474). CPG is funded by the National Institute for Health Research (NIHR-CTF-2014-03-03) as Associate Professor and Honorary Consultant Cardiologist. The Myocardial Ischaemia National Audit Project (MINAP) is commissioned by the Health Quality Improvement Partnership (HQIP) as part of the National Clinical Audit and Patient Outcomes Programme (NCAPOP). The funders had no role in study design; in the collection, analysis and interpretation of data; in the writing of the report; and in the decision to submit the article for publication. The researchers worked independently from the funders and all authors, external and internal, had full access to all of the data (including statistical reports and tables) in the study and can take responsibility for the integrity of the data and the accuracy of the data analysis.

Competing interests All authors have completed the Unified Competing Interest form (available on request from the corresponding author) and 
declare that (1) ATY has support from AstraZeneca, Bristol-Myers-Squibb and Sanofi-Aventis outside the submitted work; (2) TBD, MH, ADT, PDB, G0, $\mathrm{OAA}, \mathrm{PN}, \mathrm{JED}, \mathrm{KB}, \mathrm{HH}$ and $\mathrm{CPG}$ have no relationships with any companies that might have an interest in the submitted work in the previous 3 years; (3) their spouses, partners or children have no financial relationships that may be relevant to the submitted work; and (4) TBD, MH, ADT, PDB, G0, OAA, PN, JED, KB, HH, ATY and CPG have no non-financial interests that may be relevant to the submitted work.

Ethics approval Ethical approval was not required under NHS research governance arrangements. The National Institute for Cardiovascular Outcomes Research (NICOR) that includes the Myocardial Ischaemia National Audit Project (MINAP) database (Ref: NIGB: ECC 1-06 (d)/2011) has support under section 251 of the National Health Service (NHS) Act 2006 to use patient information for medical research without consent.

Provenance and peer review Not commissioned; externally peer reviewed.

Data sharing statement No additional data are available.

Open Access This is an Open Access article distributed in accordance with the terms of the Creative Commons Attribution (CC BY 4.0) license, which permits others to distribute, remix, adapt and build upon this work, for commercial use, provided the original work is properly cited. See: http:// creativecommons.org/licenses/by/4.0/

\section{REFERENCES}

1. Chung SC, Gedeborg R, Nicholas O, et al. Acute myocardial infarction: a comparison of short-term survival in national outcome registries in Sweden and the UK. Lancet 2014;383:1305-12.

2. Chung SC, Sundström J, Gale CP, et al. Comparison of hospital variation in acute myocardial infarction care and outcome between Sweden and the United Kingdom. BMJ 2015;351:h3913.

3. National Institute for Health and Care Excellence. NICE support for commissioning for acute coronary syndromes (including myocardial infarction). National Institute for Health and Care Excellence, 2014. http://guidance.nice.org.uk/sfcqs68 (accessed 23 Oct 2015).

4. Weston C, Gavalova L, Whittaker T, et al. Myocardial Ischaemia National Audit Project. How the NHS cares for patients with heart attack: Annual Public Report April 2013-March 2014. In: NICOR, ed. Padcreative, 2014. https://www.ucl.ac.uk/nicor/audits/minap/ documents/annual reports/minap-public-report-2014 (accessed 28 Oct 2015)

5. Fox KA, Dabbous OH, Goldberg RJ, et al. Prediction of risk of death and myocardial infarction in the six months after presentation with acute coronary syndrome: prospective multinational observational study (GRACE). BMJ 2006;333:1091.

6. Polonski L, Gasior M, Gierlotka M, et al. A comparison of ST elevation versus non-ST elevation myocardial infarction outcomes in a large registry database: are non-ST myocardial infarctions associated with worse long-term prognoses? Int $J$ Cardiol 2011;152:70-7.

7. Abbott JD, Ahmed HN, Vlachos HA, et al. Comparison of outcome in patients with ST-elevation versus non-ST-elevation acute myocardial infarction treated with percutaneous coronary intervention (from The National Heart, Lung, and Blood Institute Dynamic Registry). Am J Cardiol 2007;100:190-5.

8. Roffi M, Patrono C, Collet JP, et al. 2015 ESC Guidelines for the management of acute coronary syndromes in patients presenting without persistent ST-segment elevation: Task Force for the Management of Acute Coronary Syndromes in Patients Presenting without Persistent ST-Segment Elevation of the European Society of Cardiology (ESC). Eur Heart J 2016;37:267-315.

9. Gale C, Cattle B, Moore J, et al. Impact of missing data on standardised mortality ratios for acute myocardial infarction: evidence from the Myocardial Ischaemia National Audit Project (MINAP) 2004-7. Heart 2011;97:1926-31.

10. Lord Carter of Coles. Review of operational productivity in NHS providers: interim report. Department of Health, 2015. https://www gov.uk/government/uploads/system/uploads/attachment_data/file/ 434202/carter-interim-report.pdf (accessed 26 Oct 2015).

11. Simms AD, Weston CF, West RM, et al. Mortality and missed opportunities along the pathway of care for ST-elevation myocardial infarction: a national cohort study. Eur Heart J Acute Cardiovasc Care 2015;4:241-53.

12. Dondo TB, Hall M, Timmis AD, et al. Excess mortality and guidelineindicated care following non-ST-elevation myocardial infarction. Eur Heart J Acute Cardiovasc Care. [Epub ahead of print 3 May 2016].
13. O'Brien E, Subherwal S, Roe MT, et al. Do patients treated at academic hospitals have better longitudinal outcomes after admission for non-ST-elevation myocardial infarction? Am Heart J 2014;167:762-9.

14. McNamara RL, Chung SC, Jernberg $T$, et al. International comparisons of the management of patients with non-ST segment elevation acute myocardial infarction in the United Kingdom, Sweden, and the United States: the MINAP/NICOR, SWEDEHEART/RIKS-HIA, and ACTION Registry-GWTG/NCDR registries. Int J Cardiol 2014;175:240-7.

15. Fox KA, Goodman SG, Anderson FA Jr, et al. From guidelines to clinical practice: the impact of hospital and geographical characteristics on temporal trends in the management of acute coronary syndromes. The Global Registry of Acute Coronary Events (GRACE). Eur Heart J 2003;24:1414-24.

16. Yusuf S, Flather M, Pogue J, et al. Variations between countries in invasive cardiac procedures and outcomes in patients with suspected unstable angina or myocardial infarction without initial ST elevation. OASIS (Organisation to Assess Strategies for Ischaemic Syndromes) Registry Investigators. Lancet 1998;352:507-14.

17. A comparison of recombinant hirudin with heparin for the treatment of acute coronary syndromes. The Global Use of Strategies to Open Occluded Coronary Arteries (GUSTO) Ilb investigators. N Engl J Med 1996;335:775-82.

18. Thygesen $\mathrm{K}$, Alpert JS, Jaffe AS, et al. Third universal definition of myocardial infarction. Eur Heart J 2012;33:2551-67.

19. Herrett E, Smeeth L, Walker L, et al. The myocardial ischaemia national audit project (MINAP). Heart 2010;96:1264-7.

20. López-Sendó J, Swedberg K, McMurray J, et al. Expert consensus document on $\beta$-adrenergic receptor blockers. The Task Force on Beta-Blockers of the European Society of Cardiology. Eur Heart $J$ 2004;25:1341-62.

21. Hamm CW, Bassand JP, Agewall S, et al. ESC Guidelines for the management of acute coronary syndromes in patients presenting without persistent ST-segment elevation. The Task Force for the management of acute coronary syndromes (ACS) in patients presenting without persistent ST-segment elevation of the European Society of Cardiology (ESC). Eur Heart J 2011;32:2999-3054.

22. DH Vascular Programme Team. Treatment of Heart Attack National Guidance: final report of the National Infarct Project (NIAP). London: Department of Health, 2011. http://www.bcis.org.uk/resources/ documents/NIAP\%20Final\%20Report.pdf (accessed 13 Jul 2015).

23. Erhardt L, Herlitz J, Bossaert L, et al. Task force on the management of chest pain. Eur Heart $J$ 2002;23:1153-76.

24. Bassand JP, Hamm CW, Ardissino D, et al. Guidelines for the diagnosis and treatment of non-ST-segment elevation acute coronary syndromes. Eur Heart J 2007;28:1598-660.

25. Bertrand $M$, Simoons $M$, Fox K, et al. Management of acute coronary syndromes: acute coronary syndromes without persistent ST segment elevation. Recommendations of the Task Force of the European Society of Cardiology. Eur Heart J 2000;21:1406-32.

26. Simms AD, Baxter PD, Cattle BA, et al. An assessment of composite measures of hospital performance and associated mortality for patients with acute myocardial infarction. Analysis of individual hospital performance and outcome for The National Institute for Cardiovascular Outcomes Research (NICOR). Eur Heart $J$ Acute Cardiovasc Care 2013;2:9-18.

27. Longenecker JC, Alfaddagh A, Zubaid M, et al. Adherence to ACC/ AHA performance measures for myocardial infarction in six Middle-Eastern countries: association with in-hospital mortality and clinical characteristics. Int J Cardiol 2013;167:1406-11.

28. Simms AD, Batin PD, Weston CF, et al. An evaluation of composite indicators of hospital acute myocardial infarction care: a study of 136,392 patients from the Myocardial Ischaemia National Audit Project. Int J Cardiol 2013;170:81-7.

29. Rasmussen JN, Chong A, Alter DA. Relationship between adherence to evidence-based pharmacotherapy and long-term mortality after acute myocardial infarction. JAMA 2007;297:177-86.

30. Wei L, Wang J, Thompson P, et al. Adherence to statin treatment and readmission of patients after myocardial infarction: a six year follow up study. Heart 2002;88:229-33.

31. Christiansen CL, Morris CN. Hierarchical Poisson regression modeling. Am Stat Assoc 1997;92:618-32.

32. Simms AD, Reynolds S, Pieper K, et al. Evaluation of the NICE mini-GRACE risk scores for acute myocardial infarction using the Myocardial Ischaemia National Audit Project (MINAP) 2003-2009: National Institute for Cardiovascular Outcomes Research (NICOR). Heart 2013;99:35-40.

33. Desai NR, Bradley SM, Parzynski CS, et al. Appropriate use criteria for coronary revascularization and trends in utilization, patient 
selection, and appropriateness of percutaneous coronary intervention. JAMA 2015;314:2045-53.

34. Appleby J, Raleigh V, Frosini F, et al. Variations in health care: the good, the bad and the inexplicable. London: The King's Fund, 2011.

35. Alderwick H, Robertson R, Appleby J, et al. Better value in the NHS the role of changes in clinical practice. London: The King's Fund, 2015. http://www.kingsfund.org.uk/sites/files/kf/field/field publication_file/better-value-nhs-Kings-Fund-July\%202015.pdf (accessed 12 Oct 2015).

36. Pilote L, Califf RM, Sapp S, et al. Regional variation across the United States in the management of acute myocardial infarction. N Engl J Med 1995;333:565-72.

37. Birkhead JS, Weston C, Lowe D. Impact of specialty of admitting physician and type of hospital on care and outcome for myocardia infarction in England and Wales during 2004-5: observational study. BMJ 2006;332:1306-11.

38. Quinn T, Johnsen S, Gale CP, et al., Myocardial Ischaemia National Audit Project (MINAP) Steering Group. Effects of prehospital 12-lead ECG on processes of care and mortality in acute coronary syndrome: a linked cohort study from the Myocardial Ischaemia National Audit Project. Heart 2014;100:944-50.

39. Shah AS, Anand A, Sandoval Y, et al. High-sensitivity cardiac troponin I at presentation in patients with suspected acute coronary syndrome: a cohort study. Lancet 2015 386:2481-8.

40. Hall M, Laut K, Dondo T, et al. Patient and hospital determinants of primary percutaneous coronary intervention in England, 2003-2013. Heart 2016. Published Online First 5 Jan 2016. doi:10.1136/ heartjnl-2015-308616

41. Gale CP, Cattle B, Woolston A, et al. Resolving inequalities in care? Reduced mortality in the elderly after acute coronary syndromes. The Myocardial Ischaemia National Audit Project 2003-2010. Eur Heart J 2012;33:630-9.

42. Simms AD, Baxter PD, Cattle BA, et al. Do composite measures of hospital performance predict mortality in survivors of acute myocardial infarction? Analysis of individual hospital performance and outcome for The National Institute for Cardiovascular Outcomes Research (NICOR). Eur Heart J Acute Cardiovasc Care 2013;2:9-18.
43. Peterson ED, Roe MT, Mulgund J, et al. Association between hospital process performance and outcomes among patients with acute coronary syndromes. JAMA 2006;295:1912-20.

44. O'Gara PT, Kushner FG, Ascheim DD, et al. 2013 ACCF/AHA guideline for the management of ST-elevation myocardial infarction: a report of the American College of Cardiology Foundation/American Heart Association Task Force on Practice Guidelines. J Am Coll Cardiol 2013;61:e78-140.

45. NHS. A simple guide to Payment by Results. In: Department of Health, ed. 2011. https://www.gov.uk/government/uploads/system/ uploads/attachment_data/file/213150/PbR-Simple-Guide-FINAL.pdf (accessed 22 Jan 2016).

46. Curtin K, Beckman H, Pankow G, et al. Return on investment in pay for performance: a diabetes case study. J Healthc Manag 2006:51:365-74; discussion 375-6.

47. Doran T, Fullwood C, Kontopantelis E, et al. Effect of financial incentives on inequalities in the delivery of primary clinical care in England: analysis of clinical activity indicators for the quality and outcomes framework. Lancet 2008;372:728-36.

48. Wang JJ, Cha J, Sebek KM, et al. Factors related to clinical quality improvement for small practices using an EHR. Health Serv Res 2014;49:1729-46.

49. Sutton M, Nikolova S, Boaden R, et al. Reduced mortality with hospital pay for performance in England. $N$ Engl J Med 2012;367:1821-8

50. Wang TY, Dai D, Hernandez AF, et al. The importance of consistent, high-quality acute myocardial infarction and heart failure care: results from the American Heart Association's Get with the Guidelines Program. J Am Coll Cardiol 2011;58:637-44.

51. Eapen ZJ, Fonarow GC, Dai D, et al. Comparison of composite measure methodologies for rewarding quality of care: an analysis from the American Heart Association's Get With The Guidelines program. Circ Cardiovasc Qual Outcomes 2011;4:610-18.

52. Gabriel KR, Sokal RR. A new statistical approach to geographic variation analysis. Syst Biol 1969;18:259-78.

53. Bhatt DL, Drozda JP, Shahian DM, et al. ACC/AHA/STS statement on the future of registries and the performance measurement Enterprise: a report of the American College of Cardiology/American Heart Association Task Force on performance measures and the society of thoracic surgeons. J Am Coll Cardiol 2015;66:2230-45. 